\title{
EVALUATION OF SATISFACTION OF STUDENTS OF DOCTOR OF PHYSICAL THERAPY REGARDING THEIR FIELD OF EDUCATION.
}

\author{
Bakhtawar Wajeeha Qureshi, ,Muhammad Salman Haider Qureshi \\ Institute of Physical Medicine \& Rehabilitation \\ Peshawar Medical College
}

Corresponding author: bakhtawarqureshi.kmu@gmail.com

\begin{abstract}
To assess the satisfaction level of students of Doctor of Physical Therapy (DPT) regarding their field of education. To identify the causes responsible for dissatisfaction of students with their field of study. Physical Therapy is an emerging and growing field in Pakistan and currently is passing through its stage of infancy. Five year program of Doctor of Physical Therapy (DPT) has been now introduced resulting in increased influx of students. Yet unawareness among the students as well as society still prevailed that resulted in confusing the minds of young undergraduate students of Physical Therapy. A cross-sectional study was conducted in the Institute of Physical Medicine and Rehabilitation, Peshawar. Total 100 students of Doctor of Physical Therapy. Were interviewed through structurally designed questionnaires. Ethical consideration was taken into account. The response rate was $78 \% .55 .1 \%$ students were found satisfied with the field, $7.6 \%$ were dissatisfied while $37.1 \%$ were unable to analyze whether satisfied or dissatisfied majority being basic sciences students. Students highlighted certain factors as responsible for their dissatisfaction.Majority of the students satisfied from their field of education belonged to clinical sciences which indicate their well-aware attitude about the significance of this field. Moreover, the students held disrespectful attitude of society, Limited facilities and job opportunities and Incapable Physical Therapists imparting bad name to this profession responsible for their dissatisfaction.
\end{abstract}

\section{KEYWORDS}

Students' satisfaction, Doctor of Physical Therapy, Basic sciences, Clinical sciences, Medical education.

\section{INTRODUCTION}

Physical Therapy is an emerging and growing field in Pakistan and currently is passing through its stage of infancy. Keeping in view the recent growth and advancement of this professional in the world and its significance with regard to the health care, five year program of Doctor of Physical Therapy (DPT) has been introduced to prepare highly skilled Physical Therapists. The American Physical Therapy Association (APTA) has identified the Doctor of Physical Therapy (DPT) degree as 1 of 6 elements necessary to transition the physical therapy profession to a fully professionalized discipline. (Johanson, 2005) Fortunately, this resulted in increased influx of students in this field of education. Yet unawareness of the students as well as society regarding the importance of this particular field has resulted in developing confusion in the minds of young undergraduate students of Physical Therapy which influence the attitudes of students towards their chosen career and their perceptions of employment possibilities. So there was a need to conduct a study in order to assess the level of satisfaction of the students regarding their field and to pin point the reasons responsible for the dissatisfaction of students after joining the field of physical therapy.

\section{Methodology:}

A cross-sectional study was performed in the Institute of Physical Medicine and Rehabilitation (IPMR), Khyber Medical University Peshawar among the students of Doctor of Physical Therapy a Total of 100 students (35 male and 65 female) from 1st, 2nd, 3rd and 4th year were included in study. 1st and 2nd year students categorized as basic sciences and 3rd and 4th year students as clinical sciences were interviewed through structurally designed questionnaires with an aim to compare their views. Whereas confidentiality of subjects were taken into account. The data analysis was carried out on SPSS version 16.00

\section{RESULTS}

The response rate was $78 \%$. After analyzing the results it was revealed that about $43(55.1 \%)$ students were satisfied with the field, 6 (7.6\%) were dissatisfied while 29 $(37.1 \%)$ were unable to analyze whether satisfied or dissatisfied.

Table 1: Percentage calculation of students' remarks.

\begin{tabular}{|l|l|}
\hline & \\
\hline Satisfied & $55.10 \%$ \\
\hline Dissatisfied & $7.60 \%$ \\
\hline Confused & $37.10 \%$ \\
\hline
\end{tabular}

Out of 43 students who were satisfied, 20 were basic sciences students and 23 were clinical sciences students whereas out of 6 students who were dissatisfied, 3 were basic sciences students and 3 were clinical sciences students. While among 29 students who were confused, 24 belonged to basic sciences and only 5 belonged to clinical sciences. Students also highlighted the factors as responsible for dissatisfaction including Limited job opportunities, Lack of facilities, Incapable Physical Therapists imparting bad name to this profession, Having no council and disrespectful attitude of society and Doctors.

Table 2: Table showing feedback of clinical and basic sciences students separately.

\begin{tabular}{|l|l|l|l|}
\hline & Satisfied & Dissatisfied & Confused \\
\hline $\begin{array}{l}\text { Basic sciences } \\
\text { Students }\end{array}$ & 20 & 3 & 24 \\
\hline clinical sciences students & 23 & 3 & 5 \\
\hline
\end{tabular}




\section{DISCUSSION}

Attitudes of students towards their chosen career can also play a role in reshaping their perceptions of employment possibilities (Gotlib, 2012). And this attitude is result of society's feedback a little negativity can give birth to confusions and It is necessary that these confusions of young minds regarding their profession (here Doctor of Physical Therapy) must be cleared to produce better future doctors of Physical Therapy.

Studies regarding exploring the effects of physiotherapy student characteristics on satisfaction with their teaching and performance in assessment (Walid El Ansari, 2003) seemed to be fruitful. Studies showed that those who perceived the Doctor of Physical Therapy or DPT as being "important" did not have noticeably different perceptionsfrom those who did not perceive it as important. (Jette, 2005) Sex, ethnicity, mode of study and entry qualification etc also influences students' performance and contentment (Walid El Ansari, 2003).

This study showed that Public's unaware remarks and attitude can cause to raise doubtful and confused mind-set of present students and future doctors of Physical Therapy, yet inclusion of Doctorate degree in field of Physical Therapy showed great upheaval regarding influx of students in this field. The American Physical Therapy Association (APTA) has identified the Doctor of Physical Therapy (DPT) degree as 1 of 6 elements necessary to transition the physical therapy profession to a fully professionalized discipline. (Johanson, 2005) Students enrolled in DPT degree programs were more likely to report that the degree conferred, availability of the DPT degree, and the curriculums were more important. (Johanson, 2005) and the only thing that bothered the young minds were few social factors that can be reduced by their increased exposure to clinical side as clinical sciences students views were found more satisfactory than students of basic sciences because of their relatively more practical knowledge of the field. Also physical therapist educators must determine whether, and to what degree, the professional socialization of students during their professional education programs affects students' professional values (Johanson, 2005). The emphasis of this study was on highlighting the troublesome factors for the young students by presenting their own perception about the field and their attitude and to recommend and raise the point clear from results that there is a need of increased practical exposure of students plus to fulfill fully or nearly the fundamental needs of present students for positive results and more satisfactory future doctors of Physical therapy.

\section{CONCLUSION}

After analyzing the results it was revealed that most of the students satisfied from their field of education belonged to clinical sciences. this indicates that these students were more well aware about the significance and value of their field. Whereas the basic sciences students having less exposure to their filed showed confused attitude. Moreover, on the whole the students held certain factors such as disrespectful attitude of society, Limited facilities and job opportunities and Incapable Physical Therapists imparting bad name to this profession responsible for their dissatisfaction.

\section{REFERENCES}

- A Normative Model of Physical Therapist Professional Education, Version 97. Alexandria, Va: American Physical Therapy Association; 1997:72-73.

- Accredited Education Programs for the Physical Therapist. Alexandria, Va: American Physical Therapy Association; 2001.

- Conine TA. (1972). A survey of the graduates of a professional physical therapy program. Phys Ther, 52; 855-861.

- Educational programs leading to qualifications as a physical therapist. Phys Ther. 1991; 71:997-1004.

- Gotlib, J., Białoszewski, D., Opavsky, J., Garrod, R., Fuertes, N. E., Gallardo, L. P., ... \& Kunicka, I. (2012). Attitudes of European physiotherapy students towards their chosen career in the context of different educational systems and legal regulations pertaining to the practice of physiotherapy: implications for university curricula. Physiotherapy, 98(1), 76-85.

- Jette, A. M. (2005). A future with increased rather than diminished research capabilities. Physical Therapy, 85(8), 710-711.

- Johanson, M. A. (2005). Association of importance of the doctoral degree with students' perceptions and anticipated activities reflecting professionalism. Physical therapy, 85(8), 766-781.

- Student SuwqA Description of Students and Their Attitudes Regarding Their Education Alexandria, Va: American Physical Therapy Association; 1991.

- The Beginnings: Physical Therapy and the APTA. Alexandria, Va: American Physical Therapy Association; 1979.

- Walid El Ansari. (2003). Satisfaction Trends in Undergraduate Physiotherapy Education Physiotherapy, 89(3), 171-185 